CLINICAL STUDY

\title{
GLP-1 analogues as a new treatment option for hypothalamic obesity in adults: report of nine cases
}

\author{
Flavius Zoicas, Michael Droste ${ }^{1}$, Bernhard Mayr, Michael Buchfelder ${ }^{2}$ and Christof Schöfl \\ Division of Endocrinology and Diabetes, Department of Medicine 1, Friedrich-Alexander-University Erlangen-Nuremberg, Ulmenweg 18, 91054 Erlangen, \\ Germany, ${ }^{1}$ Endocrine Practice, Oldenburg, Germany and ${ }^{2}$ Department of Neurosurgery, Friedrich-Alexander-University Erlangen-Nuremberg, \\ Erlangen, Germany \\ (Correspondence should be addressed to C Schöfl; Email: christof.schoefl@uk-erlangen.de)
}

\begin{abstract}
Background: Patients with hypothalamic pathology often develop morbid obesity, causing severe metabolic alterations resulting in increased morbidity and mortality. Glucagon-like peptide-1 (GLP-1) analogues improve glycaemic control in type 2 diabetic patients and cause weight loss in obese patients by yet unknown mechanisms. Here we tested whether GLP-1 analogues were also effective in the treatment of obesity and associated metabolic alterations in patients with hypothalamic disease.

Methods: Nine patients (eight with type 2 diabetes mellitus) with moderate to severe hypothalamic obesity were treated with GLP-1 analogues for up to 51 months. Body weight, homeostasis model assessment - insulin resistance (HOMA-IR), HbAlc and lipids were assessed.

Results: Eight patients experienced substantial weight loss $(-13.1 \pm 5.1 \mathrm{~kg}$ (range -9 to -22$)$ ). Insulin resistance (HOMA-IR $-3.2 \pm 3.5$ (range -9.1 to 0.8$)$ ) and HbA1c values $(-1.3 \pm 1.4 \%$ (range -4.5 to 0.0)) improved under treatment (24.3 18.9 months (range 6 to 51)). Five patients reported increased satiation in response to the treatment. Two of the eight patients complained about nausea and vomiting and one of them abandoned therapy because of sustained gastrointestinal discomfort after 6 months. One patient suffered from intolerable nausea and vomiting and discontinued treatment within 2 weeks.

Conclusion: GLP-1 analogues can cause substantial and sustained weight loss in obese patients with hypothalamic disease. This offers a new approach for medical treatment of moderate to severe hypothalamic obesity and associated metabolic alterations.
\end{abstract}

European Journal of Endocrinology 168 699-706

\section{Introduction}

Patients with brain tumours such as craniopharyngiomas, which involve the hypothalamic region, are at high risk for the development of obesity $(1,2,3,4,5,6,7,8)$. Hypothalamic obesity appears to result from tumouror treatment-related damage of hypothalamic nuclei especially in the ventromedial region that causes impairment of mechanisms controlling satiety, hunger and energy expenditure $(9,10,11,12)$. At presentation, about $15 \%$ of adult patients suffering from a craniopharyngioma complain about excessive weight gain or are obese $(1,2,7,13)$. During long-term followup, excessive weight gain has been reported in up to $67 \%$ of craniopharyngioma patients after surgery with or without adjuvant radiotherapy $(1,2,3,4,7,14)$. Hypothalamic obesity is often associated with disastrous metabolic and psychological consequences leading to severe morbidity, impaired quality of life and reduced life expectancy $(2,7)$. Features of the metabolic syndrome such as abdominal obesity, dyslipidaemia, hyperinsulinaemia caused by insulin resistance and elevated blood pressure are commonly seen in these patients $(2,3,7,15,16)$, which contribute to the increased risk for cardiovascular morbidity and long-term mortality $(2,7,16,17,18)$.

Thus, the necessity for treatment is vital but treatment of hypothalamic obesity is difficult and often intractable. In the affected patients, weight gain is mostly unresponsive to diet and exercise interventions. Targeted pharmacological treatment is limited and consists of suppression of insulin secretion with octreotide and/or sympathomimetics $(19,20,21,22)$. Methylphenidate, a dopamine reuptake inhibitor, has been shown to reduce energy intake and especially the intake of fat (23). Furthermore, in animal studies, methylphenidate increased locomotor activity $(24,25)$ and thus might be a helpful compound to overcome physical hypoactivity, which is common in patients with hypothalamic obesity $(10,19,26)$. Orlistat, a gastrointestinal lipase inhibitor, has limited efficacy and can be associated with intolerable side effects that can preclude its use $(27,28)$. Several other drugs have recently been withdrawn from the market due to severe 
side effects, e.g. sibutramine, which was associated with a high risk of cardiovascular events (29). Therefore, bariatric surgery remains the only option for the treatment of morbid hypothalamic obesity (30, 31). Depending on the surgical intervention, however, patients require life-long surveillance and nutritional supplementation (30). Thus, there is a clear need for novel therapeutic options, which are both effective and well tolerated with an acceptable long-term safety profile.

Analogues of glucagon-like peptide-1 (GLP-1), which is a gut-derived incretin hormone, are used for the treatment of type 2 diabetes mellitus. They stimulate secretion, thereby improving glycaemic control (32). In addition, treatment with GLP-1 analogues promotes significant weight loss in diabetic as well as non-diabetic obese subjects $(33,34,35,36)$. GLP-1 receptors are expressed in the stomach, duodenum and exocrine pancreas as well as in several hypothalamic and brainstem nuclei involved in appetite regulation (37, $38,39,40)$. Although the precise mechanisms that mediate the effects of GLP-1 analogues on weight reduction are yet to be unravelled, there may be a well as on the brain $(37,38,40)$. It is unknown whether GLP-1 analogues can lead to weight loss in patients with obesity caused by hypothalamic damage, and whether these compounds could be an option for their treatment. We therefore treated nine patients with moderate to severe hypothalamic obesity with a GLP-1 analogue and assessed changes in weight and metabolic parameters such as insulin resistance, $\mathrm{HbAlc}$ and lipid metabolism.

\section{Materials and methods}

Nine patients with tumours involving the hypothalamic region and obesity were treated either with the GLP-1 analogue exenatide (eight) or with liraglutide (one). Six patients had a craniopharyngioma, one a pilocytic astrocytoma, a germinoma and a hypothalamic hamartoma respectively. Eight patients had at least one operation, and one of them received adjunctive radiotherapy. The patient with a germinoma was irradiated only. All patients suffered from partial $(n=2)$ or panhypopituitarism $(n=7)$ with or without central diabetes insipidus and received hormone replacement therapy (Table 1), which had been optimized prior to GLP-1 analogue therapy. Eight patients suffered from type 2 diabetes mellitus. The patients were examined regularly and body weight and blood pressure were recorded. Blood glucose, HbA1c, total cholesterol, HDL- and LDL-cholesterol, and triglycerides were measured by routine laboratory methods from fasting blood samples. Insulin was determined by a chemiluminescence immunoassay (Immulite 2000; Siemens, Eschborn, Germany). Insulin sensitivity was quantified by calculating HOMA-IR glucose-dependent insulin release and inhibit glucagon combination of effects on the gastrointestinal tract as

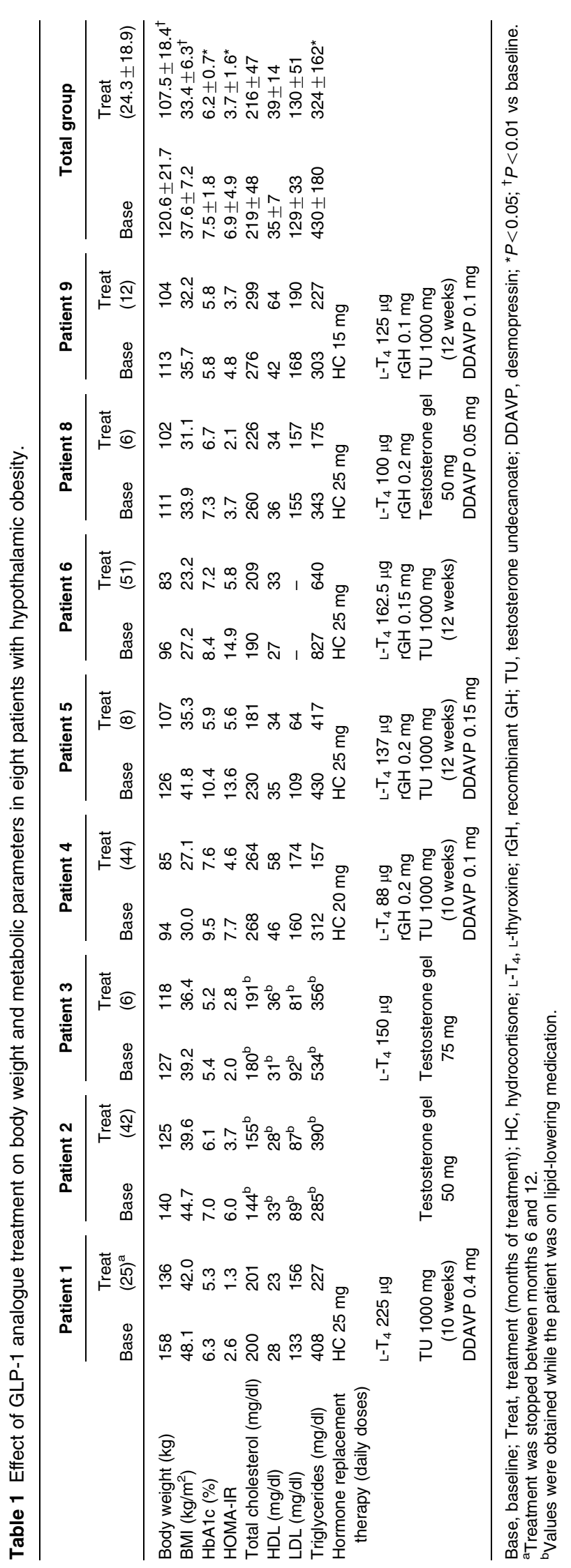

www.eje-online.org 
using fasting glucose and insulin values and the HOMA2 program which was kindly provided by Dr Levy $(41,42)$.

Values are means \pm s.D. Statistical analysis was performed using SigmaPlot version 11 (Systat Software, Erkrath, Germany). Pre- and post-treatment data were compared by the Wilcoxon signed-rank test for paired comparisons. Significance was considered at $P<0.05$.

\section{Case reports and results}

\section{Patient 1}

A 49-year-old Caucasian man complained about $30 \mathrm{~kg}$ of weight gain within 6 months, intermittent headaches, insomnia, lethargy, polydipsia, nocturia and impairment of vision. Type 2 diabetes mellitus was diagnosed and further investigations revealed a cystic tumour arising in the sellar region and extending to the hypothalamus on a cranial magnetic resonance imaging (MRI). The patient was operated twice in April 2007 and August 2007 via a transcranial route with complete tumour removal of an adamantinomatous craniopharyngioma. Post-surgery, the patient suffered from persistent panhypopituitarism and diabetes insipidus. Despite adequate hormonal replacement therapy (Table 1), good glycaemic control under metformin therapy (1000 mg BID) and repeated dietary and lifestyle counselling, no weight loss could be achieved (Fig. 1). In January 2010, treatment with exenatide ( $5 \mu$ g s.c. once daily) was started. The patient reported a feeling of satiety with significantly reduced meal sizes. He lost a maximum of $34 \mathrm{~kg}$ of weight within 8 months of therapy (Fig. 1). Dyslipidaemia, insulin resistance and $\mathrm{HbA1c}$ improved (Fig. 2A, B and C) as well as subjective quality of life. No adverse events of exenatide were reported. Exenatide was paused for 6 months. Remarkably, his body weight and metabolic parameters remained fairly stable during this period. As reported by the patient, his physical fitness had substantially improved in response to weight loss, so that he could exercise on a regular basis. Thus, it appears that maintenance of body weight was primarily achieved by lifestyle changes rather than by a delayed action of exenatide. Thereafter, exenatide ( $5 \mu$ g s.c. once daily) was restarted and in October 2011, the dose was increased to $5 \mu \mathrm{g}$ twice daily because of a moderate weight gain. Under this therapy, body weight stabilized, $\mathrm{HbA1c}$ was $5.3 \%$, triglycerides further improved, but a slight increase in insulin resistance and cholesterol levels were observed (Table 1 and Fig. 1).

\section{Patient 2}

Patient 2 was a 46-year-old Caucasian man who suffered from a pilocytic astrocytoma (WHO I) within the third ventricle. The tumour was excised in 2002 and a ventriculoperitoneal shunt was installed. In 2006, a cranial MRI showed two new lesions, one in the suprachiasmatic region close to the third ventricle $(18 \times 10 \times 17 \mathrm{~mm})$ and a second one in the left thalamus $(9 \times 8 \mathrm{~mm})$. A fronto-temporal trepanation was performed and both tumours were completely removed. Post-surgery, the patient developed partial hypopituitarism with GH deficiency and hypogonadism (treatment, see Table 1). Furthermore, the patient experienced a continuous and considerable weight gain, reaching a maximum BMI of $44.7 \mathrm{~kg} / \mathrm{m}^{2}$, and developed dyslipidaemia, type 2 diabetes mellitus, arterial hypertension and obstructive sleep apnoea syndrome. The patient was put on metformin $(2000 \mathrm{mg} /$ day $)$ and in July 2008 , treatment with exenatide $(5 \mu \mathrm{g}$ s.c. twice daily) was initiated and further uptitrated to $10 \mu \mathrm{g}$ BID. Within the first 2 years of treatment, the patient lost $20 \mathrm{~kg}$ of body weight, which remained relatively stable after that. Glycaemic control improved over time, but dyslipidaemia remained unchanged (Table 1). The patient reported a normal appetite and a sensation of satiety, which he did not have prior to exenatide treatment. No adverse events were reported.

\section{Patient 3}

A 17-year-old man, who suffered from drug-resistant epilepsy, underwent a partial left-sided temporal lobectomy in September 2006, and in October 2008, a hypothalamic hamartoma $(10 \times 6 \mathrm{~mm})$ in the lower left-side part of the third ventricle was excised and a callosotomy was performed. After the second operation, the patient complained about a weight gain of $40 \mathrm{~kg}$ in 6 months (maximum BMI $39.2 \mathrm{~kg} / \mathrm{m}^{2}$ ),

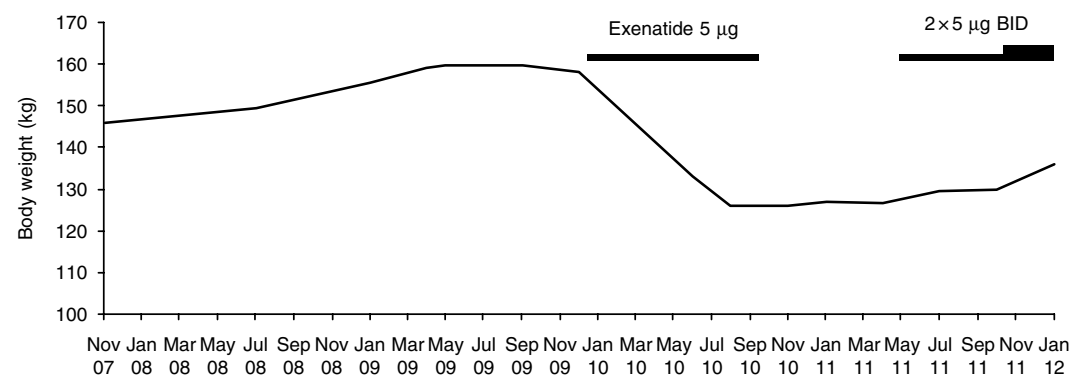

Figure 1 Changes in body weight in response to exenatide therapy in case 1 . 

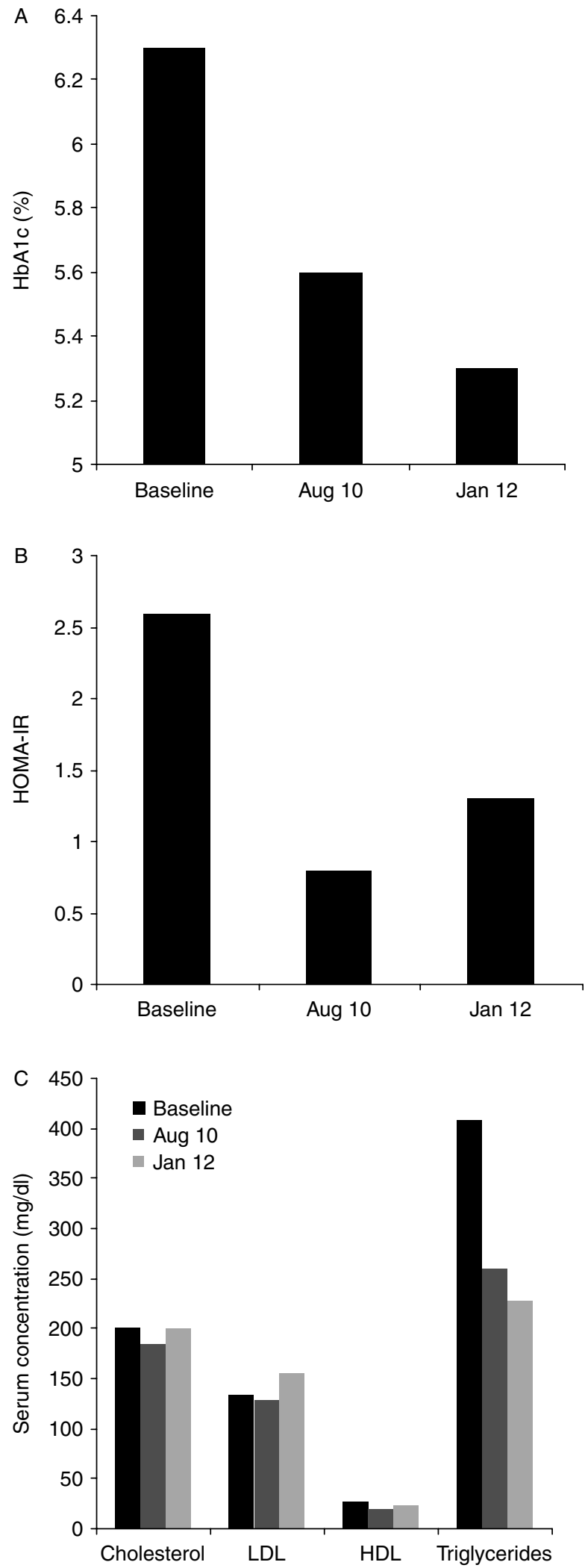

Figure 2 Changes in HbA1c (A), HOMA-IR (B) and lipids (C) in response to exenatide therapy in case 1. a loss of sensation of thirst and satiety, and a general hypodynamia. Partial hypopituitarism was diagnosed with alterations in the somatotrope, gonadotrope and thyrotrope axis (treatment, see Table 1). Furthermore, moderate hypertriglyceridaemia developed. The patient was put on metformin (850 mg BID) and methylphenidate (10 mg once daily) in order to counteract weight gain and hypoactivity. This treatment approach, however, was not tolerated because of gastrointestinal side effects and several grand mal seizures, which developed under this treatment. Therefore, off-label treatment with exenatide ( $5 \mu \mathrm{g}$ BID) was started. Within 6 months of treatment, the patient lost $9 \mathrm{~kg}$ of body weight. Concerning insulin resistance and dyslipidaemia, however, no improvement was noticed (Table 1).

\section{Patient 4}

A 35-year-old man experienced headaches, psychotic changes and polydipsia. A suprasellar craniopharyngioma extending to the hypothalamus $(20 \times 30 \mathrm{~mm})$ was diagnosed and a transfrontal operation was performed in 1997. Post-surgery, the patient suffered from panhypopituitarism and diabetes insipidus (treatment, see Table 1). The patient experienced continuous weight gain and in 2001, type 2 diabetes mellitus was diagnosed. Despite metformin (850 mg TID), the patient put on further weight, reaching a BMI of $30 \mathrm{~kg} / \mathrm{m}^{2}$, and glycaemic control was unsatisfactory (HbAlc 9.5\%). In April 2008, therapy with exenatide ( $5 \mu \mathrm{g}$ BID) was initiated. Upon treatment, the patient reported for the first time a sufficient sensation of satiety since the operation in 1997. Despite nausea and intermittent vomiting, he insisted on continuing therapy because of an overall subjective improvement of quality of life. Over 44 months of treatment, the patient lost $9 \mathrm{~kg}$ of weight (BMI $27.5 \mathrm{~kg} / \mathrm{m}^{2}$ ), and glycaemic control and dyslipidaemia improved (Table 1).

\section{Patient 5}

Patient 5 is a Caucasian man born in 1974 who presented with polyuria and polydipsia at the age of 22 years. A suprasellar germinoma was diagnosed and the patient received radiation therapy. Postirradiation, he developed panhypopituitarism, which was treated as depicted in Table 1. In 2002, type 2 diabetes mellitus was diagnosed and treated with metformin $(3 \times 850 \mathrm{mg}$ daily). Because of insufficient glycaemic control (HbA1c 8.4\%), the patient was switched to exenatide ( $5 \mu \mathrm{g}$ s.c. BID) in September 2007. At that time, his BMI was $27.2 \mathrm{~kg} / \mathrm{m}^{2}$. After 51 months of treatment, the patient had lost $13 \mathrm{~kg}$ and reached normal weight (BMI $23.2 \mathrm{~kg} / \mathrm{m}^{2}$ ), and his $\mathrm{HbA1c}$ as well as dyslipidaemia had improved (Table 1). Initially, the patient reported nausea but no vomiting, which subsided with time. 


\section{Patient 6}

Patient 6 was born in 1959. At the age of 47 years, he developed headaches and visual impairment. A large suprasellar craniopharyngioma was diagnosed and the tumour was operated via a transcranial route. Postoperatively he developed panhypopituitarism and central diabetes insipidus, which was treated as given in Table 1 . The patient gained $10 \mathrm{~kg}$ of body weight and in 2006, type 2 diabetes mellitus was diagnosed. Metformin therapy $(2 \times 1000 \mathrm{mg})$ was initiated but glycaemic control was moderate (HbAlc 7.3\%) and obesity (BMI $33.9 \mathrm{~kg} / \mathrm{m}^{2}$ ) persisted. Exenatide treatment with $5 \mu \mathrm{g}$ s.c. BID was started in September 2009. After the first week of therapy, the patient reported that his binge-eating disorder had vanished. However, because of uncontrolled vomiting even with the lowest dose of $5 \mu \mathrm{g}$ exenatide once per day, the treatment was stopped after 6 months. Within this short period of therapy, the patient lost $9 \mathrm{~kg}$ of body weight, and glycaemic control and hypertriglyceridaemia improved (Table 1).

\section{Patient 7}

A Caucasian man born in 1947 complained about headaches and deterioration of vision in 1972. A craniopharyngioma was diagnosed and the tumour was operated. Because of several relapses, multiple surgeries followed and in 1989, the patient received radiation therapy. He developed complete pituitary deficiency and diabetes insipidus as a consequence of therapy (treatment, see Table 1). Over the years, the patient became grossly obese (BMI $47.1 \mathrm{~kg} / \mathrm{m}^{2}$ ) and in 1995 , type 2 diabetes mellitus was diagnosed. Despite rigorous dietary measures and various antidiabetic drug regimens including metformin in combination with glimepiride and rosiglitazone and, later on, intensified insulin therapy, glycaemic control was unsatisfactory (HbA1c 7.9\%). Therefore, in July 2008, exenatide treatment was started ( $5 \mu \mathrm{g}$ s.c. once daily). Because of intolerable nausea and vomiting, the treatment was abandoned after 2 weeks. The patient underwent bariatric surgery (gastric banding). At the last visit, BMI was $40 \mathrm{~kg} / \mathrm{m}^{2}$ and under metformin monotherapy (850 mg BID), HbA1c was 5.3\%.

\section{Patient 8}

A 38-year-old man presented with $20 \mathrm{~kg}$ weight gain within several months and was diagnosed with a papillary craniopharyngioma in 2006. The tumour was operated via a transcranial route. Post-surgery, the patient suffered from panhypopituitarism and diabetes insipidus, for which he was treated (Table 1). Postoperatively, his body weight further increased by $13 \mathrm{~kg}$ and in 2008, type 2 diabetes mellitus was diagnosed, which was treated with metformin (850 mg BID).
In May 2010, exenatide was started (5 $\mu \mathrm{g}$ BID). The patient reported an increased sensation of satiety and after 12 months of therapy, the patient had lost $9 \mathrm{~kg}$ of body weight. HbA1c remained unchanged, while insulin resistance and triglyceride levels improved (Table 1).

\section{Patient 9}

Patient 9 was born in 1971 and was diagnosed with an adamantinomatous craniopharyngioma in 2008, which was transcranially excised. After surgery, the patient developed complete pituitary deficiency, diabetes insipidus, severe obesity and type 2 diabetes mellitus, which were treated as depicted in Table 1. Because of poor glycaemic control (HbAlc 10.4\%) and a BMI of $41.8 \mathrm{~kg} / \mathrm{m}^{2}$, treatment with liraglutide $(0.6 \mathrm{mg} /$ day $)$ was commenced in October 2010. The patient reported less hunger and an increased feeling of satiety. After 8 months of therapy, the patient showed significant weight loss, reaching a BMI of $35.3 \mathrm{~kg} / \mathrm{m}^{2}$, had improved glycaemic control and insulin resistance, as well as decreased cholesterol levels (Table 1).

In this series of nine patients with obesity caused or aggravated by hypothalamic pathology and/or its therapy, treatment with GLP-1 analogues was relatively well tolerated. Five patients reported increased satiation after meals, which they had not experienced prior to the treatment. Three patients reported nausea and vomiting, of whom one patient stopped therapy after 2 weeks and another one after 6 months. In the third patient, symptoms subsided and therapy was continued. In the eight patients who received treatment for at least 6 months $(24.3 \pm 18.9$ months, range $6-51)$, the average weight loss amounted to $13.1 \pm 5.1 \mathrm{~kg}$ (range 9-22; $P<0.01)$ and BMI decreased from $37.6 \pm 7.2$ to $33.4 \pm$ $6.3 \mathrm{~kg} / \mathrm{m}^{2}(P<0.01)$. The average daily dosages were $11.4 \pm 3.8 \mu \mathrm{g}$ for exenatide and $0.6 \mathrm{mg}$ for liraglutide. HbA1c improved by $1.3 \pm 1.4 \%(P<0.05$, range $0-4.5)$ and insulin sensitivity improved as indicated by HOMAIR, which decreased from $6.9 \pm 4.9$ to $3.7 \pm 1.6$ $(P<0.05)$. With the exception of triglycerides, which dropped from $430 \pm 180$ to $324 \pm 162 \mathrm{mg} / \mathrm{dl}$ $(P<0.05)$, no improvement in lipid parameters (total, HDL- or LDL-cholesterol) was observed.

\section{Discussion}

Body weight control is complex involving several brain regions, orexigenic and anorexigenic pathways, as well as central and peripheral signalling molecules that regulate food intake as well as energy consumption and locomotor activity $(43,44,45)$. Within this complex interplay, the hypothalamus is considered as one of the key structures for processing and integration of central and peripheral pathways and signals. Consistently, patients with tumours involving the hypothalamus are often hypoactive and complain about increased food 
intake and a loss of satiety sensation $(2,7,9,10,11)$. Consequently, they develop severe obesity and obesityassociated morbidities such as dyslipidaemia, diabetes mellitus and cardiovascular disease (1, 2, 3, 7). Both structural and functional disruptions of regulatory pathways may explain why attempts to reduce and control body weight by employing behavioural interventions or drug treatments fail in most patients. Even with bariatric surgery, which often remains the only option in morbidly obese patients, sustained weight loss may not be achieved and outcome data are conflicting $(4,30,31,46)$.

In this case series, treatment with GLP-1 analogues promoted substantial weight loss in eight of the nine patients with hypothalamic obesity. This could be sustained for as long as 51 months, which was the longest observation period in this series. Weight loss was associated with a favourable metabolic and cardiovascular risk profile as insulin resistance, glycaemic control and hypertriglyceridaemia significantly improved under treatment. Cholesterol levels, however, did not change, which is consistent with the results from some but not all randomized trials reporting about the effects of GLP-1 analogue treatment on lipids $(34,36)$. The effects on body weight and metabolic parameters were at least as pronounced as previously reported from obese diabetic and non-diabetic patients without hypothalamic pathology $(33,34,35,36)$. Interestingly, the average daily drug doses required were relatively low and in one patient even below the recommended minimal daily dose (47). Thus, it appears that some patients with hypothalamic obesity are rather sensitive to GLP analogue therapy. Fortunately, it seems that this does not necessarily apply to the most common adverse effects of this therapy, namely nausea and vomiting. This is of interest as in patients with type 2 diabetes, an association between increased nausea and weight loss has been suggested (48). Our observation, however, is consistent with studies from animal models that show that GLP-1-dependent actions on food intake and visceral illness can be dissociated $(40,49)$ and are confined to distinct brain areas (40).

The mechanism whereby exogenous GLP-1 or its analogues trigger weight loss is only incompletely understood. As GLP-1 receptors are expressed in the brain as well as in peripheral tissues, weight loss might be caused by a combination of central and peripheral GLP-1 actions $(37,38,40,50)$. In the brain, GLP-1 acts to increase energy expenditure and to reduce food intake according to animal studies $(38,40)$. With respect to the inhibition of food intake, this involves GLP-1 receptor activation in the paraventricular nucleus of the hypothalamus, the hindbrain and in the nuclei of the mesolimbic reward system $(37,38,40,51)$. In addition, there is good experimental evidence that peripheral GLP-1 via activation of peripheral GLP-1 receptors and through the activation of afferent vagal neurotransmission from the intestine could reduce meal sizes and increase satiation $(37,38,40)$. Clinical data from human studies suggest that weight loss in patients treated with GLP-1 or its analogues is predominantly caused by decreased food intake rather than through changes in energy expenditure (40). This may involve delayed gastric emptying and increased satiation caused by peripheral and central actions of exogenous GLP-1 (38, 40, 52).

It can be assumed that in our patients, damages to the structure and function of hypothalamic nuclei were quite heterogeneous as the underlying pathologies differed in size, local extension and treatment. Despite this, all eight patients who tolerated the treatment lost weight, which indicates either that none of our patients had damaged hypothalamic structures relevant for GLP-1 analogue-induced weight loss or that mechanisms were involved that do not require intact hypothalamic functioning. Whatever the mechanisms are, our series clearly demonstrates that GLP-1 analogues are capable of inducing weight loss in patients with obesity caused or aggravated by hypothalamic damage. Although this is not a controlled study and the number of treated patients was relatively small, treatment with GLP-1 analogues holds promise as a novel therapeutic option to reduce or control body weight and to improve metabolic co-morbidities in these patients. It remains to be shown which patients with hypothalamic obesity profit most from GLP analogue therapy.

\section{Declaration of interest}

The authors declare that there is no conflict of interest that could be perceived as prejudicing the impartiality of the research reported.

\section{Funding}

This work is part of the Neurotrition Project, which is supported by the FAU Emerging Fields Initiative.

\section{References}

1 Karavitaki N, Brufani C, Warner JT, Adams CB, Richards P, Ansorge O, Shine B, Turner HE \& Wass JA. Craniopharyngiomas in children and adults: systematic analysis of 121 cases with long-term follow-up. Clinical Endocrinology 200562 397-409. (doi:10.1111/j.1365-2265.2005.02231.x)

2 Karavitaki N, Cudlip S, Adams CB \& Wass JA. Craniopharyngiomas. Endocrine Reviews 200627 371-397. (doi:10.1210/er. 2006-0002)

3 Kendall-Taylor P, Jonsson PJ, Abs R, Erfurth EM, KoltowskaHaggstrom M, Price DA \& Verhelst J. The clinical, metabolic and endocrine features and the quality of life in adults with childhoodonset craniopharyngioma compared with adult-onset craniopharyngioma. European Journal of Endocrinology 2005152 557-567. (doi:10.1530/eje.1.01877)

4 Müller HL, Gebhardt U, Teske C, Faldum A, Zwiener I, Warmuth-Metz M, Pietsch T, Pohl F, Sörensen N \& Calaminus G. Post-operative hypothalamic lesions and obesity in childhood craniopharyngioma: results of the multinational prospective trial KRANIOPHARYNGEOM 2000 after 3-year follow-up. European Journal of Endocrinology 2011165 17-24. (doi:10.1530/EJE-110158) 
5 Sorva R. Children with craniopharyngioma. Early growth failure and rapid postoperative weight gain. Acta Paediatrica Scandinavica 198877 587-592. (doi:10.1111/j.1651-2227.1988.tb10705.x)

6 Stahnke N, Grubel G, Lagenstein I \& Willig RP. Long-term followup of children with craniopharyngioma. European Journal of Pediatrics 1984142 179-185. (doi:10.1007/BF00442445)

7 Zoicas F \& Schöfl C. Craniopharyngioma in adults. Frontiers in Endocrinology 20123 46. (doi:10.3389/fendo.2012.00046)

8 Sklar CA. Craniopharyngioma: endocrine sequelae of treatment. Pediatric Neurosurgery 199421 (Suppl 1) 120-123. (doi:10.1159/ 000120873)

9 Daousi C, Dunn AJ, Foy PM, MacFarlane IA \& Pinkney JH. Endocrine and neuroanatomic features associated with weight gain and obesity in adult patients with hypothalamic damage. American Journal of Medicine 2005118 45-50. (doi:10.1016/j. amjmed.2004.06.035)

10 Harz KJ, Müller HL, Waldeck E, Pudel V \& Roth C. Obesity in patients with craniopharyngioma: assessment of food intake and movement counts indicating physical activity. Journal of Clinical Endocrinology and Metabolism 200388 5227-5231. (doi:10.1210/jc.2002-021797)

11 Holmer H, Pozarek G, Wirfalt E, Popovic V, Ekman B, Bjork J \& Erfurth EM. Reduced energy expenditure and impaired feeding related signals but not high energy intake reinforces hypothalamic obesity in adults with childhood onset craniopharyngioma. Journal of Clinical Endocrinology and Metabolism 201095 5395-5402. (doi:10.1210/jc.2010-0993)

12 Schöfl C, Schleth A, Berger D, Terkamp C, von zur Mühlen A \& Brabant G. Sympathoadrenal counterregulation in patients with hypothalamic craniopharyngioma. Journal of Clinical Endocrinology and Metabolism 200287 624-629. (doi:10.1210/ jc.87.2.624)

13 Mortini P, Losa M, Pozzobon G, Barzaghi R, Riva M, Acerno S, Angius D, Weber G, Chiumello G \& Giovanelli M. Neurosurgical treatment of craniopharyngioma in adults and children: early and long-term results in a large case series. Journal of Neurosurgery 2011114 1350-1359. (doi:10.3171/2010.11.JNS10670)

14 Hoffman HJ, De Silva M, Humphreys RP, Drake JM, Smith ML \& Blaser SI. Aggressive surgical management of craniopharyngiomas in children. Journal of Neurosurgery $1992 \mathbf{7 6} 47-52$. (doi:10.3171/jns.1992.76.1.0047)

15 Holmer H, Ekman B, Bjork J, Nordstom CH, Popovic V, Siversson A \& Erfurth EM. Hypothalamic involvement predicts cardiovascular risk in adults with childhood onset craniopharyngioma on longterm GH therapy. European Journal of Endocrinology $2009 \mathbf{1 6 1}$ 671-679. (doi:10.1530/EJE-09-0449)

16 Pereira AM, Schmid EM, Schutte PJ, Voormolen JH, Biermasz NR, van Thiel SW, Corssmit EP, Smit JW, Roelfsema F \& Romijn JA. High prevalence of long-term cardiovascular, neurological and psychosocial morbidity after treatment for craniopharyngioma. Clinical Endocrinology 200562 197-204. (doi:10.1111/j.13652265.2004.02196.x)

17 Bülow B, Attewell R, Hagmar L, Malmström P, Nordström CH \& Erfurth EM. Postoperative prognosis in craniopharyngioma with respect to cardiovascular mortality, survival, and tumor recurrence. Journal of Clinical Endocrinology and Metabolism $1998 \mathbf{8 3}$ 3897-3904. (doi:10.1210/jc.83.11.3897)

18 Tomlinson JW, Holden N, Hills RK, Wheatley K, Clayton RN, Bates AS, Sheppard MC \& Stewart PM. Association between premature mortality and hypopituitarism. West Midlands Prospective Hypopituitary Study Group. Lancet $2001357425-431$. (doi:10.1016/S0140-6736(00)04006-X)

19 Bereket A, Kiess W, Lustig RH, Müller HL, Goldstone AP, Weiss R, Yavuz Y \& Hochberg Z. Hypothalamic obesity in children. Obesity Reviews 201213 780-798. (doi:10.1111/j.1467-789X.2012. 01004.x)

20 Greenway FL \& Bray GA. Treatment of hypothalamic obesity with caffeine and ephedrine. Endocrine Practice 200814 697-703.

21 Lustig RH, Hinds PS, Ringwald-Smith K, Christensen RK, Kaste SC, Schreiber RE, Rai SN, Lensing SY, Wu S \& Xiong X. Octreotide therapy of pediatric hypothalamic obesity: a double-blind, placebo-controlled trial. Journal of Clinical Endocrinology and Metabolism 200388 2586-2592. (doi:10.1210/jc.2002-030003)

22 Mason PW, Krawiecki N \& Meacham LR. The use of dextroamphetamine to treat obesity and hyperphagia in children treated for craniopharyngioma. Archives of Pediatrics \& Adolescent Medicine 2002156 887-892. (doi:10.1001/archpedi.156.9.887)

23 Goldfield GS, Lorello C \& Doucet E. Methylphenidate reduces energy intake and dietary fat intake in adults: a mechanism of reduced reinforcing value of food? American Journal of Clinical Nutrition 200786 308-315.

24 Askenasy EP, Taber KH, Yang PB \& Dafny N. Methylphenidate (Ritalin): behavioral studies in the rat. International Journal of Neuroscience 2007117 757-794. (doi:10.1080/00207450600 910176)

25 Walker QD, Morris SE, Arrant AE, Nagel JM, Parylak S, Zhou G, Caster JM \& Kuhn CM. Dopamine uptake inhibitors but not dopamine releasers induce greater increases in motor behavior and extracellular dopamine in adolescent rats than in adult male rats. Journal of Pharmacology and Experimental Therapeutics 2010 335 124-132. (doi:10.1124/jpet.110.167320)

26 Elfers CT \& Roth CL. Effects of methylphenidate on weight gain and food intake in hypothalamic obesity. Frontiers in Endocrinology 20112 78. (doi:10.3389/fendo.2011.00078)

27 Rucker D, Padwal R, Li SK, Curioni C \& Lau DC. Long term pharmacotherapy for obesity and overweight: updated metaanalysis. BMJ 2007335 1194-1199. (doi:10.1136/bmj.39385. 413113.25)

28 Siebenhofer A, Horvath K, Jeitler K, Berghold A, Stich AK, Matyas E, Pignitter $\mathrm{N}$ \& Siering U. Long-term effects of weight-reducing drugs in hypertensive patients. Cochrane Database of Systematic Reviews 2009. Article Number CD007654. (doi:10.1002/14651858.CD007654.pub2)

29 Glandt M \& Raz I. Present and future: pharmacologic treatment of obesity. Journal of Obesity 20112011 636181. (doi:10.1155/ 2011/636181)

30 Inge TH, Pfluger P, Zeller M, Rose SR, Burget L, Sundararajan S, Daniels SR \& Tschöp MH. Gastric bypass surgery for treatment of hypothalamic obesity after craniopharyngioma therapy. Nature Clinical Practice. Endocrinology \& Metabolism 20073 606-609. (doi:10.1038/ncpendmet0579)

31 Page-Wilson G, Wardlaw SL, Khandji AG \& Korner J. Hypothalamic obesity in patients with craniopharyngioma: treatment approaches and the emerging role of gastric bypass surgery. Pituitary 201215 84-92. (doi:10.1007/s11102-011-0349-5)

32 Holst JJ. The physiology of glucagon-like peptide 1. Physiological Reviews 200787 1409-1439. (doi:10.1152/physrev.00034. 2006)

33 Apovian CM, Bergenstal RM, Cuddihy RM, Qu Y, Lenox S, Lewis MS \& Glass LC. Effects of exenatide combined with lifestyle modification in patients with type 2 diabetes. American Journal of Medicine 2010123 468.e9-468.e17. (doi:10.1016/j.amjmed. 2009.11.019)

34 Astrup A, Rössner S, Van Gaal L, Rissanen A, Niskanen L, Al Hakim M, Madsen J, Rasmussen MF \& Lean ME. Effects of liraglutide in the treatment of obesity: a randomised, doubleblind, placebo-controlled study. Lancet $2009 \mathbf{3 7 4}$ 1606-1616. (doi:10.1016/S0140-6736(09)61375-1)

35 Rosenstock J, Klaff LJ, Schwartz S, Northrup J, Holcombe JH, Wilhelm K \& Trautmann M. Effects of exenatide and lifestyle modification on body weight and glucose tolerance in obese subjects with and without pre-diabetes. Diabetes Care 201033 1173-1175. (doi:10.2337/dc09-1203)

36 Vilsboll T, Christensen M, Junker AE, Knop FK \& Gluud LL. Effects of glucagon-like peptide-1 receptor agonists on weight loss: systematic review and meta-analyses of randomised controlled trials. BMJ $2012 \mathbf{3 4 4}$ d7771. (doi:10.1136/bmj.d7771)

37 Abu-Hamdah R, Rabiee A, Meneilly GS, Shannon RP, Andersen DK \& Elahi D. Clinical review: the extrapancreatic 
effects of glucagon-like peptide-1 and related peptides. Journal of Clinical Endocrinology and Metabolism 2009 94 1843-1852. (doi:10.1210/jc.2008-1296)

38 Barrera JG, Sandoval DA, D'Alessio DA \& Seeley RJ. GLP-1 and energy balance: an integrated model of short-term and longterm control. Nature Reviews. Endocrinology 20117 507-516. (doi:10.1038/nrendo.2011.77)

39 Larsen PJ, Fledelius C, Knudsen LB \& Tang-Christensen M. Systemic administration of the long-acting GLP-1 derivative NN2211 induces lasting and reversible weight loss in both normal and obese rats. Diabetes 200150 2530-2539. (doi:10.2337/ diabetes.50.11.2530)

40 Tong J \& Sandoval DA. Is the GLP-1 system a viable therapeutic target for weight reduction? Reviews in Endocrine \& Metabolic Disorders 201112 187-195. (doi:10.1007/s11154-011-9170-8)

41 Levy JC, Matthews DR \& Hermans MP. Correct homeostasis model assessment (HOMA) evaluation uses the computer program. Diabetes Care 199821 2191-2192. (doi:10.2337/diacare.21.12.2191)

42 Wallace TM, Levy JC \& Matthews DR. Use and abuse of HOMA modeling. Diabetes Care 200427 1487-1495. (doi:10.2337/ diacare.27.6.1487)

43 Kalra SP \& Kalra PS. Neuroendocrine control of energy homeostasis: update on new insights. Progress in Brain Research 2010181 17-33. (doi:10.1016/S0079-6123(08)81002-3)

44 Vianna CR \& Coppari R. A treasure trove of hypothalamic neurocircuitries governing body weight homeostasis. Endocrinology 2011152 11-18. (doi:10.1210/en.2010-0778)

45 Woods SC \& D'Alessio DA. Central control of body weight and appetite. Journal of Clinical Endocrinology and Metabolism 200893 S37-S50. (doi:10.1210/jc.2008-1630)

46 Weismann D, Pelka T, Bender G, Jurowich C, Fassnacht M, Thalheimer A \& Allolio B. Bariatric surgery for morbid obesity in craniopharyngioma. Clinical Endocrinology $2013 \mathbf{7 8} 385-390$. (doi:10.1111/j.1365-2265.2012.04409.x)
47 Bray GM. Exenatide. American Journal of Health-System Pharmacy 200663 411-418. (doi:10.2146/ajhp050459)

48 Garber A, Henry R, Ratner R, Garcia-Hernandez PA, RodriguezPattzi H, Olvera-Alvarez I, Hale PM, Zdravkovic M \& Bode B. Liraglutide versus glimepiride monotherapy for type 2 diabetes (LEAD-3 Mono): a randomised, 52-week, phase III, doubleblind, parallel-treatment trial. Lancet $2009 \quad 373 \quad 473-481$. (doi:10.1016/S0140-6736(08)61246-5)

49 Lachey JL, D’Alessio DA, Rinaman L, Elmquist JK, Drucker DJ \& Seeley RJ. The role of central glucagon-like peptide-1 in mediating the effects of visceral illness: differential effects in rats and mice. Endocrinology 2005146 458-462. (doi:10.1210/en. 2004-0419)

50 Ahren B. GLP-1 and extra-islet effects. Hormone and Metabolic Research 200436 842-845. (doi:10.1055/s-2004-826173)

51 Alhadeff AL, Rupprecht LE \& Hayes MR. GLP-1 neurons in the nucleus of the solitary tract project directly to the ventral tegmental area and nucleus accumbens to control for food intake. Endocrinology 2012153 647-658. (doi:10.1210/en. 2011-1443)

52 Willms B, Werner J, Holst JJ, Orskov C, Creutzfeldt W \& Nauck MA. Gastric emptying, glucose responses, and insulin secretion after a liquid test meal: effects of exogenous glucagon-like peptide-1 (GLP-1)-(7-36) amide in type 2 (noninsulin-dependent) diabetic patients. Journal of Clinical Endocrinology and Metabolism $1996 \mathbf{8 1}$ 327-332. (doi:10.1210/jc.81.1.327)

Received 13 November 2012

Revised version received 21 December 2012

Accepted 7 February 2013 